\title{
Protective effect of vanillin in streptozotocin-induced diabetes in neonatal rats via attenuation of oxidative stress and inflammation
}

\author{
Guoyan Lu ${ }^{1,2}$, Xingling Luo ${ }^{1,2}$, Zhongqiang Liu ${ }^{1,2}$, Lin Yang ${ }^{1,2}$, Chao Lin ${ }^{1,2}$, Min \\ $\mathbf{X u}^{1,2 *}$
}

${ }^{1}$ Department of Pediatric, West China Second University Hospital, Sichuan University, ${ }^{2}$ Key Laboratory of Birth Defects and Related Diseases of Women and Children, Sichuan University, Ministry of Education, Chengdu, Sichuan 610041, China

*For correspondence: Email: MeaderMsas@yahoo.com; Tel/Fax: 0086-18081891989

\begin{abstract}
Purpose: To evaluate the antidiabetic activity of vanillin in streptozotocin (STZ)-induced diabetic rats. Methods: Diabetes was induced in 2-day old male pups by intraperitoneal (i.p.) administration of STZ $(90 \mathrm{mg} / \mathrm{kg})$. The pups were then randomly assigned to four groups: control group which received citrate buffer only in place of STZ; negative control group, i.e., diabetic group; and vanillin-treated groups which received vanillin (100 or $200 \mathrm{mg} / \mathrm{kg}$, p.o.) continuously from the 6th week of age to the 10 th week. The antidiabetic effect of vanillin was determined by measuring the serum levels of insulin, triglycerides and glucose in the diabetic rats. Oral glucose tolerance, kidney and liver function tests were also performed at the end of the protocol. Moreover, the oxidative stress and inflammatory cytokines in liver tissues, and histopathological changes in pancreatic tissues were assessed.

Results: Vanillin treatment significantly decreased serum glucose and triglyceride levels and increased the level of insulin, when compared to the negative control group. There was higher insulin sensitivity in the vanillin-treated group than in the negative control group. In addition, vanillin improved liver and renal functions in STZ-induced diabetic neonatal rats. Hepatic oxidative stress and inflammatory mediators, as well as histopathological changes in pancreas were attenuated by vanillin treatment.

Conclusion: These results reveal that vanillin attenuates hyperglycemia in STZ-induced neonatal diabetic rat model by decreasing oxidative stress and inflammatory cytokines. There, further studies are required to develop the anti-diabetic potentials of vanillin for clinical applications.
\end{abstract}

Keywords: Vanillin, Streptozotocin, Diabetes, Oxidative stress, Insulin, Neonatal

\begin{abstract}
This is an Open Access article that uses a funding model which does not charge readers or their institutions for access and distributed under the terms of the Creative Commons Attribution License (http://creativecommons.org/licenses/by/4.0) and the Budapest Open Access Initiative (http://www.budapestopenaccessinitiative.org/read), which permit unrestricted use, distribution, and reproduction in any medium, provided the original work is properly credited.

Tropical Journal of Pharmaceutical Research is indexed by Science Citation Index (SciSearch), Scopus, International Pharmaceutical Abstract, Chemical Abstracts, Embase, Index Copernicus, EBSCO, African Index Medicus, JournalSeek, Journal Citation Reports/Science Edition, Directory of Open Access Journals (DOAJ), African Journal Online, Bioline International, Open-J-Gate and Pharmacy Abstracts
\end{abstract}

\section{INTRODUCTION}

Diabetes is one of the most serious metabolic disorders and a leading cause of mortality worldwide. Elevated fasting blood glucose, a characteristic feature of diabetes, occurs due to insulin resistance or insulin deficiency. The two main types of diabetes are diabetes mellitus type I (DM-I) and type II (DM-II). A study conducted in China in 2008 revealed that about 92.4 million people were diabetic [1]. 
Several hypoglycemic drugs are used in combination to control blood glucose, but they have several limitations. In the last few decades, studies have shown that alternative medicine possesses promising potential in the management of chronic disorders. Streptozotocin (STZ) is a diabetogenic agent that exerts toxic effects on the $\beta$ - cells of the pancreas [2]. It was first used to produce acute hyperglycemia in neonatal rats, and it was observed that later in adulthood, the rats suffered from hyperglycemia resembling the features of type 2 diabetes [3]. Thus, the STZ model is ideal for the screening of antidiabetic drugs that enhance the regeneration of pancreatic $\beta$ - cells.

Vanillin is often used in the industrial preparation of drugs, cosmetics, beverages and foods. It has been reported to exhibit many therapeutic effects such as anti-angiogenic and anti-mutagenic effects $[4,5]$. Studies have shown that vanillin enhances the expressions of anti-inflammatory cytokines and decreases the expressions of proinflammatory cytokines [6]. It has strong antioxidant, antimicrobial, anticonvulsant and antidepressant activities [7-10]. The present study was carried out to evaluate the antidiabetic effects of vanillin in STZ-induced diabetes in neonatal rats.

\section{EXPERIMENTAL}

\section{Animals}

Sprague-Dawley rats weighing 150 - $180 \mathrm{~g}$ were used for this study. They were used for breeding so as to produce the pups required for the study. The rats were housed under controlled conditions as per the guidelines. The experiments were approved by the Animal Ethical Committee of Huazhong University of Science \& Technology, China (approval no. HUST/IAEC/2016/11). The study followed the guidelines of the Association for the Assessment and Accreditation of Laboratory Animal Care International (AAALAC) for experimentation and animal use [11].

Diabetes was induced in 2-day old male pups by i.p. administration of $\mathrm{STZ}(90 \mathrm{mg} / \mathrm{kg}$, i.p.). Leakage of injected material was prevented by carefully ensuring that the site of injection was under the inguinal fat of the neonates. The pups were weaned at 4 weeks old and selected for screening through oral glucose tolerance test.

The animals were divided into four groups: control group which received citrate buffer only in place of STZ; negative control group i.e. diabetic group; and 2 vanillin groups which were given vanillin at doses of 100 and $200 \mathrm{mg} / \mathrm{kg} \mathrm{p.o.} \mathrm{for} 4$ weeks as from the $6^{\text {th }}$ week of age to the $10^{\text {th }}$ week.

\section{Assessment of water consumption and body weight}

Water intake was monitored throughout the treatment period i.e. 4 weeks and the rats were weighed daily. The mean body weight and mean water intake of STZ-induced neonatal diabetic rats were recorded.

\section{Evaluation of blood levels of insulin, triglycerides and glucose}

The rats were anesthetized and blood was withdrawn from the retro-orbital plexus into nonanticoagulant sample vials and allowed to clot. The serum obtained was used for insulin estimation by radioimmunoassay using a doubleantibody radioimmunoassay kit. Glucose and triglycerides were estimated colorimetrically using auto analyzer.

\section{Oral glucose tolerance test}

Glucose $(2.5 \mathrm{~g} / \mathrm{kg})$ was given orally to overnight fasted rats at the end of treatment protocol. Serum levels of insulin and glucose were estimated at $0,0.5,1,1.5$ and $2 \mathrm{~h}$ after the administration of glucose. Level of insulin and glucose in the serum at 0 and $2 \mathrm{~h}$ were used to calculate the ISI value, which is an index used to determine insulin sensitivity.

\section{Assessment of kidney and liver functions}

Kidney and liver function tests were carried out in the blood and urine. At the end of the treatment period, blood was withdrawn from the retroorbital plexus and allowed to clot. Serum aspirate aminotransferase, alanine aminotransferase and creatinine were estimated using assay kits as per the kit instructions. However, 24-h urine sample collected in metabolic cages were subjected to assays for levels of albumin, creatinine and creatinine and albumin clearance.

\section{Determination of oxidative stress parameters}

The rats were sacrificed by cervical dislocation at the end of the treatment protocol, and liver tissues were excised. The liver tissues were washed with saline and homogenized in Tris- $\mathrm{HCl}$ buffer, $\mathrm{pH}$ 7.4. Tissue debris was removed by centrifuging the homogenate at $5000 \mathrm{rpm}$. The supernatant was used for the estimation of MDA and GSH levels, and the activities of SOD and 
CAT using appropriate assay kits as per the manufacturers' instructions.

\section{Assessment of inflammatory mediators}

The inflammatory mediators (TNF- $\alpha$, MCP-1, IL-6 and IL1 $\beta$ ) were assayed in the liver tissue homogenate using Bio-plex Pro-magnetic beadbased Luminex kit as per the instruction of manufacturer. Internally, the dyed magnetic beads bound with specific anti-cytokine primary antibodies were reacted with the tissue homogenate. Then, biotinylated anti-cytokine secondary antibodies were bound to the specific cytokine-bound antibodies. Phycoerythrinconjugated streptavidin was added to the sample and analysis was done with Bio-Plex Manager software version 6.1 .

\section{Histopathological studies}

Pancreas tissues were rinsed in saline and dehydrated in increasing alcohol concentrations prior to blocking in paraffin. Tissue slices of $5-\mu \mathrm{m}$ thickness were cut from the paraffin blocks using a microtome, and slices were stained with hematoxylin and eosin. Changes in the histology of pancreatic tissue were observed under a trinocular microscope.

\section{Statistical analysis}

Data are presented as mean \pm SD $(n=8)$ and were statistically analyzed using one-way analysis of variance (ANOVA), followed by Dunnett's post hoc test with the aid of SPSS software. Statistical significance was fixed at $p<$ 0.05 .

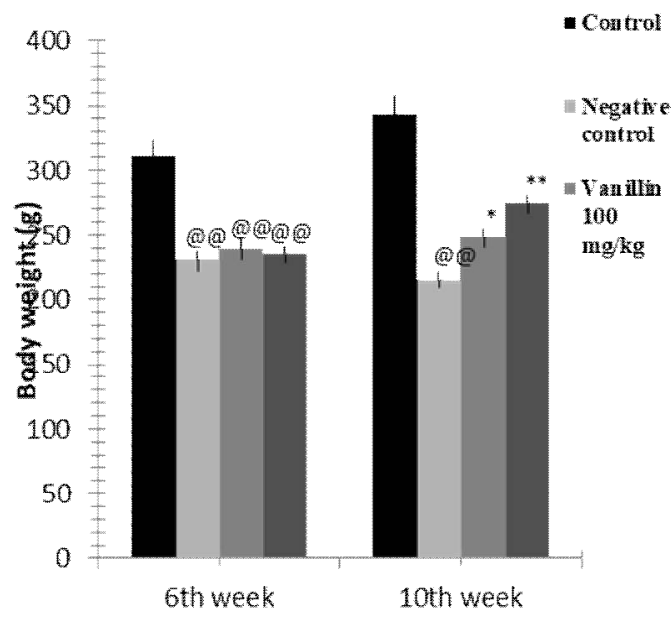

\section{RESULTS}

Effect of vanillin on water consumption and body weight of STZ-induced diabetic neonatal rats

The effect of vanillin on water consumption and body weight of STZ-induced diabetic neonatal rats is presented in Figure 1. It was observed that mean body weight of the rats was significantly decreased, when compared to control group. However, treatment with vanillin significantly reversed the diabetes-associated weight loss, relative to negative control group on $10^{\text {th }}$ week of age. There was significant increase in the water intake index in negative control group, when compared to control group. However, water intake index was significantly reduced $(p<0.01)$ in the vanillin-treated group of rats, relative to the negative control group.

\section{Effect of vanillin on serum levels of glucose, triglycerides and insulin}

Effects of vanillin on serum glucose, triglycerides, insulin and insulin sensitivity index of STZinduced diabetic neonatal rats are shown in Figure 2. There were significant increases in serum glucose and triglycerides on the $6^{\text {th }}$ week of age, when compared to control group. However, vanillin exposure significantly decreased the serum glucose and triglycerides after the $10^{\text {th }}$ week of age, when compared to the negative control group $(p<0.01)$. Blood insulin was significantly reduced in the STZ-induced diabetic rats after the $6^{\text {th }}$ week of age. However, after four weeks of treatment with vanillin, blood insulin was significantly increased, relative to the negative control group. Insulin sensitivity indices

Figure 1: Effect of vanillin on water consumption and body weight of STZ-induced diabetic neonatal rats. Values are mean $\pm \mathrm{SD}(\mathrm{n}=8)$. ${ }^{@} p<0.01$, compared to control group; ${ }^{*} p<0.05$, ${ }^{* *} p<0.01$, compared to negative control group 
were used to estimate the sensitivity of insulin. It was observed that treatment with vanillin significantly reversed the altered level of insulin sensitive index, when compared to negative control group.
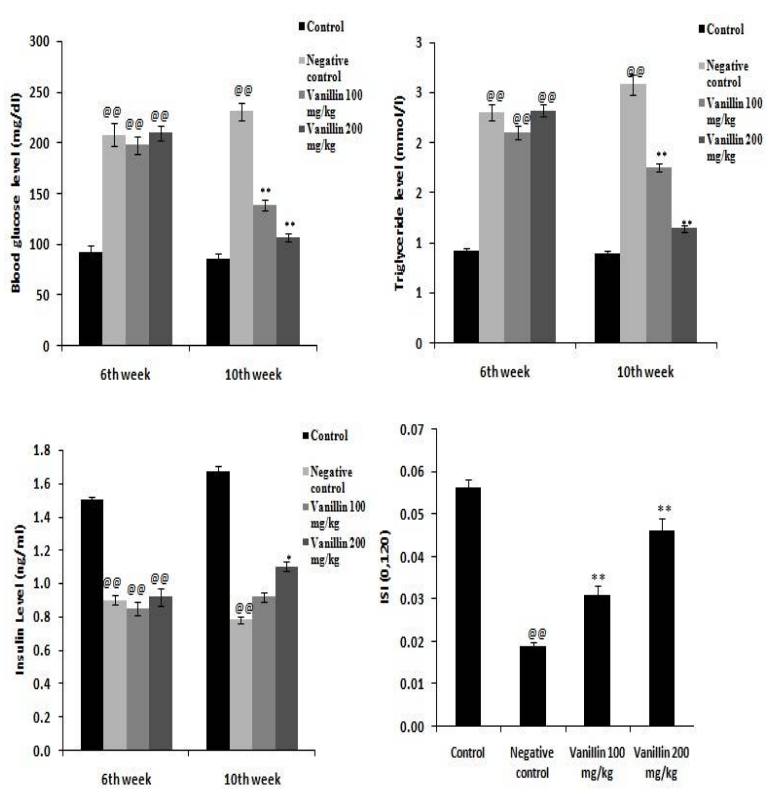

Figure 2: Effect of vanillin on serum levels of glucose, triglycerides, insulin, and insulin sensitivity indices of STZ-induced diabetic neonatal rats. Values shown as mean $\pm \mathrm{SD}(\mathrm{n}=8) .{ }^{@ @ ~} p<0.01$, compared to control group; ${ }^{*} p<0.05,{ }^{* *} p<0.01$, relative to negative control group

\section{Effect of vanillin on oral glucose tolerance test}

The effect of vanillin on oral glucose tolerance test in STZ-indiced diabetic neonatal rats is shown in Figure 3. It was observed that the AUC increased 2 to 3 folds, reflecting impaired glucose tolerance in the negative control group. However, treatment with vanillin significantly decreased the AUC, relative to the negative control group. Thus, glucose tolerance was enhanced by vanillin in STZ-induced diabetic rats.

\section{Effect of vanillin on kidney and liver functions}

Effect of vanillin on kidney and liver functions in STZ-induced neonatal diabetic rats is shown in Figure 4. It was observed that ALT, AST and creatinine levels were significantly increased in the blood of STZ-induced neonatal diabetic rats, when compared to the control group $(p<0.01)$. However, there were significant decreases in the levels of ALT, AST and creatinine in the vanillintreated group, when compared to the negative control group $(p<0.01)$. Urine and creatinine clearance were significantly enhanced in the negative control group. However, vanillin treatment significantly decreased creatinine and urea clearance, relative to the negative control group.
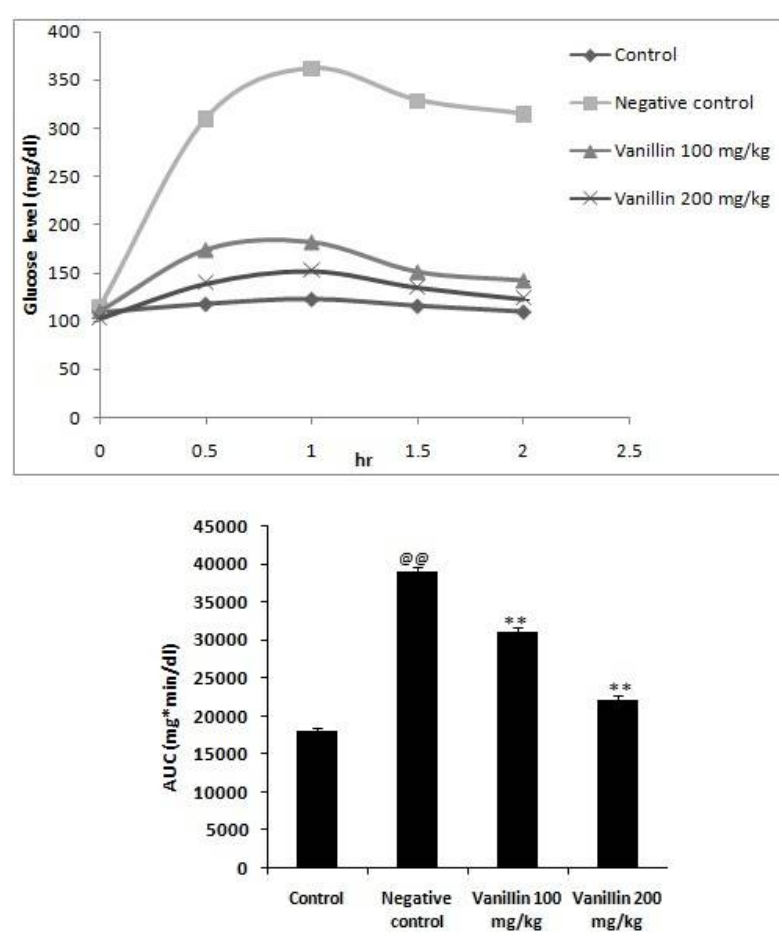

Figure 3: Effect of vanillin on oral glucose tolerance test in STZ-induced neonatal diabetic rats. Results are mean $\pm \mathrm{SD}(\mathrm{n}=8)$. $@^{@} p<0.01$, compared to control group; ${ }^{*} p<0.05,{ }^{* *} p<0.01$, compared to negative control group
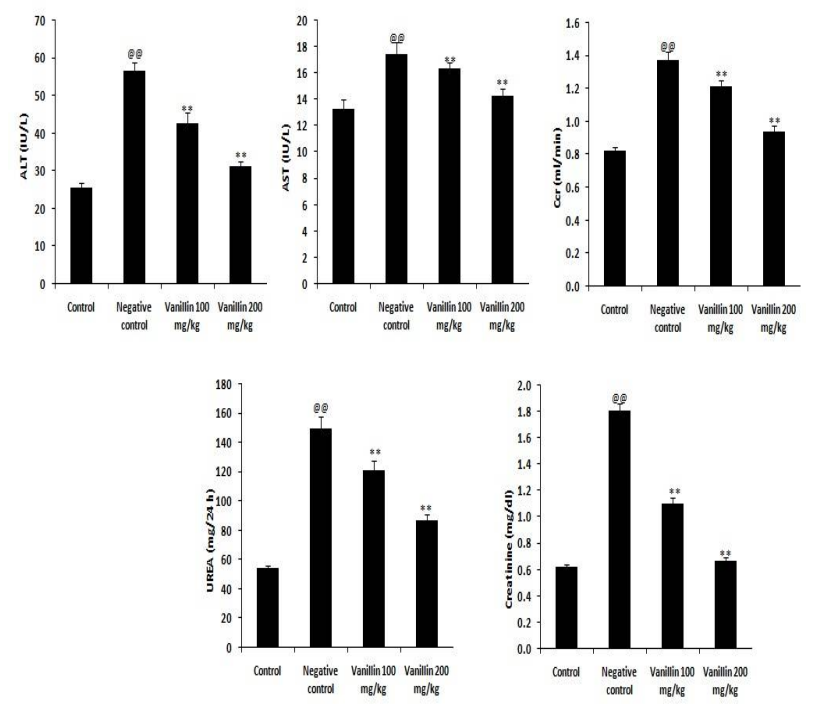

Figure 4: Effect of vanillin on the kidney and liver functions in STZ-induced diabetic neonatal rats. Results are mean $\pm \mathrm{SD}(\mathrm{n}=8) .{ }^{@ @ ~} p<0.01$, compared to control group; ${ }^{*} p<0.05,{ }^{* *} p<0.01$, compared to negative control group 


\section{Effect of vanillin on oxidative stress parameters}

Table 1 shows the effect of vanillin on the levels of LPO and GSH, and its effect on the activities of SOD and CAT in STZ-induced diabetic rats. There were significant reductions in the activities of SOD and CAT in the negative control group, when compared to control group. Lipid peroxidation (LPO) was enhanced and GSH significantly reduced in the negative control group, when compared to control group. However, treatment with vanillin reversed the changes in LPO and GSH, and activities of SOD and CAT in the STZ-induced diabetic rats.

\section{Effect of vanillin on inflammatory cytokines}

Effect of vanillin on inflammatory cytokines in STZ-induced diabetic neonatal rats is shown in Figure 5. There was significant increase in the levels of inflammatory cytokines IL-1 $\beta$, IL-6, TNF$\alpha$ and MCP-1 in the liver homogenate of the negative control group, when compared to control group. However, treatment with vanillin attenuated the altered levels of inflammatory
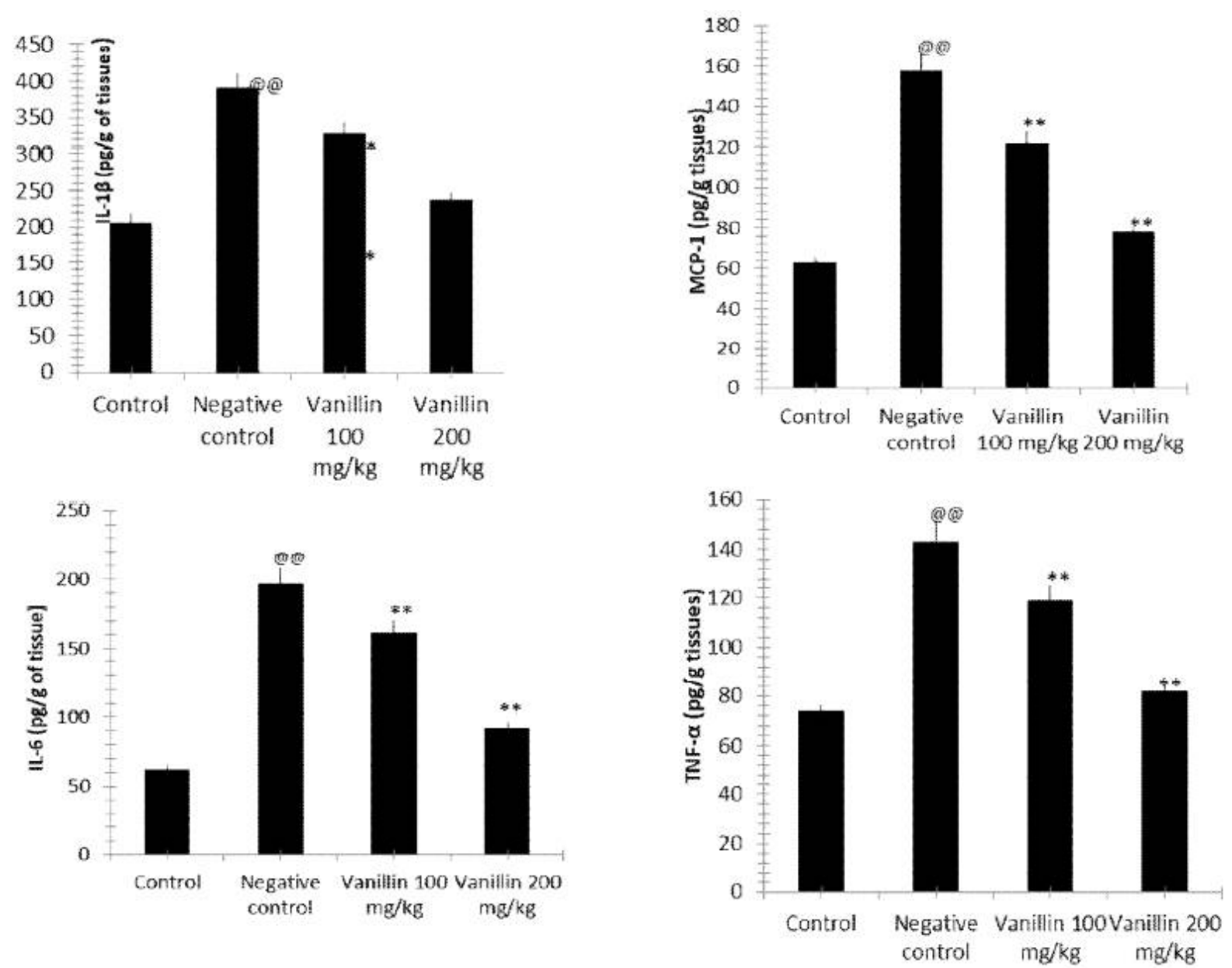

Figure 5: Effect of vanillin on inflammatory cytokines in STZ-induced diabetic neonatal rats. Values are presented as mean $\pm S D(n=8)$. ${ }^{@} p<0.01$, compared to control group; ${ }^{*} p<0.05$, ${ }^{* *} p<0.01$, compared to the negative control group

Table 1: Effect of vanillin on the level of LPO and GSH and activities of SOD and CAT in STZ-induced diabetic neonatal rats (mean $\pm S D, n=8$ )

\begin{tabular}{lcccc}
\hline Group & $\begin{array}{c}\text { SOD } \\
\text { (mg/protein) }\end{array}$ & $\begin{array}{c}\text { LPO } \\
\text { (nmol MDA/mg protein) }\end{array}$ & $\begin{array}{c}\text { CAT } \\
\text { (mg/protein) }\end{array}$ & $\begin{array}{c}\text { GSH } \\
\text { (mg/100 g of tissue) }\end{array}$ \\
\hline Control & $21.2 \pm 1.1$ & $4.2 \pm 0.23$ & $142.4 \pm 12.3$ & $31.62 \pm 1.38$ \\
Negative control & $2.3 \pm 0.25^{(\omega)}$ & $17.3 \pm 1.2^{\omega \omega}$ & $11.8 \pm 0.7^{(\infty \omega}$ & $8.19 \pm 0.32$ \\
Vanillin & $10.5 \pm 1.1^{* *}$ & $10.8 \pm 0.82^{* *}$ & $62.1 \pm 2.93^{* *}$ & $19.6 \pm 0.96$ \\
$100 \mathrm{mg} / \mathrm{kg}$ & $18.1 \pm 1.2^{* *}$ & $6.1 \pm 0.35^{* *}$ & $128.9 \pm 10.6^{* *}$ & $28.47 \pm 1.21$ \\
Vanillin & ${ }^{* *}$ & & \\
$200 \mathrm{mg} / \mathrm{kg}$ & ${ }^{* *} P<0.01$, compared to control group; ${ }^{*} p<0.05,{ }^{* *} p<0.01$, compared to negative control group
\end{tabular}


cytokines in the liver homogenate of the STZinduced diabetic rats.

\section{Effect of vanillin on histopathological features of the pancreas}

The effect of vanillin on the histopathology of pancreas in STZ-induced diabetic neonatal rats is shown in Figure 6. In the control group, the cytoplasm contained several elongated and round islets, and lightly-stained nuclei relative to the surrounding acinar cells. Histopathology of pancreas of the negative control group showed infiltration of lymphocytes, and shrunken and damaged islets. However, the vanillin treatment reduced the changes in size and degree of damage in the islets.

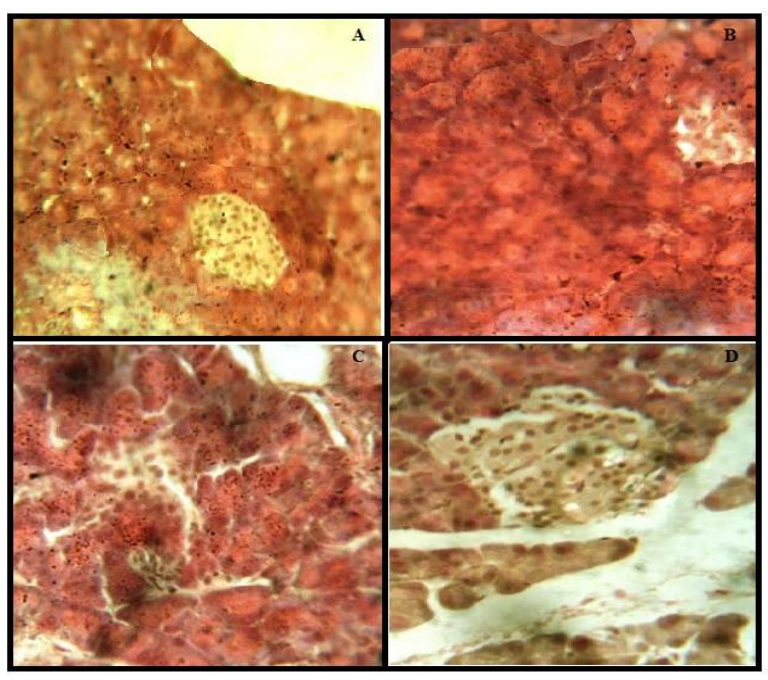

Figure 6: Effect of vanillin on the histopathology of pancreas in STZ-induced diabetic neonatal rats. A: Control, B: Negative control, C: Vanillin $100 \mathrm{mg} / \mathrm{kg}$, D: Vanillin $200 \mathrm{mg} / \mathrm{kg}$ (H \& E; x400)

\section{DISCUSSION}

In this study, the antidiabetic effect of vanillin in STZ-induced diabetes in neonatal rats was investigated. Diabetes was induced in the neonatal rats by injecting STZ, and after $6^{\text {th }}$ week of age, vanillin was given orally for the period of 4 weeks. The antidiabetic activity was assessed by estimating serum glucose, insulin and biochemical parameters of kideny and liver functions.

Previously, postprandial hyperglycemia and glucose intolerance were considered as markers of type II diabetes in which the liver enhances the production of glucose that results in increase in fasting blood glucose [11]. In type II diabetes, blood lipid levels are altered due to a correlation between the metabolisms of glucose and lipids [12]. The results obtained showed that the serum concentrations of triglycerides and glucose were significantly elevated in the diabetic group, relative to the control group. However, chronic administration of vanillin attenuated the altered concentration of glucose and lipids in diabetic rats.

Insulin promotes the metabolism of glucose and thereby reduces blood glucose levels. Thus, the mechanism of anti-diabetic drugs involves either enhancement of insulin sensitivity or promotion of insulin synthesis [13]. It is known that STZ increases blood glucose by destroying the pancreatic $\beta$ cells [14]. Uncontrolled hyperglycemia results in enhancement of inflammatory reactions and oxidative stress, leading to destruction of peripheral organs due to glucose toxicity [15]. This decreases the sensitivity of peripheral organs to insulin, thereby exacerbating diabetes. The data obtained in the present study reveal that treatment with vanillin enhances the sensitivity of insulin in diabetic rats. This increase in the sensitivity of insulin occurs by attenuating oxidative stress in STZ-induced diabetic neonatal rats. These findings are consistent with previously published data [16]. Streptozotocin (STZ)-induced destruction of the $\beta$ cells of the pancreatic tissue causes alteration in the level of insulin which results in diabetes. The histopathology of pancreatic tissue revealed that treatment with vanillin significantly attenuated the STZ-induced pancreatic $\beta$ cell injury.

\section{CONCLUSION}

The results of the present study demonstrate that vanillin exerts anti-hyperglycemic activity in STZinduced diabetes in neonatal rats by decreasing oxidative stress and enhancing insulin sensitivity. Thus, vanillin has a potential for clinical application in the management of diabetes.

\section{DECLARATIONS}

\section{Acknowledgement}

This study was supported by West China Second University Hospital, Sichuan University.

\section{Conflict of interest}

No conflict interest is associated with this study

\section{Contribution of authors}

We declare that this work was done by the authors named in this article and all liabilities pertaining to claims relating to the content of this article will be borne by the authors. All the 
experiments are performed by Guoyan Lu and Xingling Luo. Zhongqiang Liu and Lin Yang collected the materials. Chao Lin did statistical analysis. Min Xu designed the whole study and supervised the other authors.

\section{REFERENCES}

1. Yang W, Lu J, Weng J, Jia W, Ji L, Xiao J, Shan Z, Liu J, Tian H, Ji Q, Zhu D, Ge J, Lin L, Chen L, Guo X, Zhao Z, Li Q, Zhou Z, Shan G, He J, Prevalence of diabetes among men and women in China. N Engl J Med. 2010; 362: 1090-1101.

2. Tripathi AS, Mazumder PM, Chandewar AV, Evaluation of drug interaction of Glimepiride with Phosphodiesterase inhibitors Type 5 in Diabetic nephropathy. Exp Clin Endocrinol Diabetes 2014; 122 : 597-601.

3. AJF, The use of animal models in diabetes research. Br J Pharmacol. 2012; 166(3): 877-894.

4. King $A A$, Shaughnessy DT, Mure K, Leszczynska J, Ward WO, Umbach DM, Xu Z, Ducharme D, Taylor JA, Demarini DM, Klein $C B$. Antimutagenicity of cinnamaldehyde and vanillin in human cells: Global gene expression and possible role of DNA damage and repair. Mutat Res. 2007; 616: 60-69.

5. Dhingra $D$, Sharma A, Evaluation of antidepressant-like activity of glycyrrhizin in mice. Indian J Pharmacol. 2005; 37: 390-394.

6. Park S, Sim Y, Choi S, Seo Y, Kwon M, Lee J, Suh HW., Anti-nociceptive profiles and mechanisms of orally administered vanillin in the mice. Arch Pharm Res 2009; 32: 1643-1649.

7. Bhagwat V, Chowta MN, Shoeb A, Maskeri R, Venkatesh $V$, Rai A., Evaluation of anxiolytic activity of vanillin in wistar albino rats. Int $J$ Nutr Pharmacol Neurol Dis. 2013; 3: 96-101.
8. Ngarmsak $M$, Delaquis $P$, Toivonen $P$, Ngarmsak $T$, Ooraikul B, Mazza G. Antimicrobial activity of vanillin against spoilage microorganisms in stored fresh-cut mangoes. J Food Prot. 2006; 69: 1724-1727.

9. Al-Goblan AS, Al-Alfi MA, and Khan MZ, Mechanism linking diabetes mellitus and obesity. Diabetes Metab Syndr Obes. 2014; 7: 587-591.

10. Cai Z, Li F, Peng C, Li H, Zong Y, Liu Z, Qu S, Effect of insulin on the differential expression of VLDL receptor isoforms of SGC7901 cell and its biological implication. J Huazhong Univ Sci Technolog Med Sci. 2010; 30: 551-555.

11. Guide for the Care and Use of Laboratory Animals: Eighth Edition Committee for the Update of the Guide for the Care and Use of Laboratory Animals; National Research Council. 2010; ISBN: 0-309-15401-4.

12. Siddiqui AA, Siddiqui SA, Ahmad S, Siddiqui S, Ahsan I, Sahu K., Diabetes: Mechanism, Pathophysiology and Management-A Review. Int J Drug Dev \& Res, 2013; 5(2): 1-23.

13. Lam CJ, Jacobson DR, Rankin MM, Cox AR, Kushner $J A, \beta$ Cells Persist in T1D Pancreata without Evidence of Ongoing $\beta$-Cell Turnover or Neogenesis. J Clin Endocrinol Metab. 2017; 102: 2647-2659.

14. Celik S, Erdogan S, Tuzcu M, Caffeic acid phenethyl ester (CAPE) exhibits significant potential as an antidiabetic and liver-protective agent in streptozotocin induced diabetic rats. Pharmacol Res. 2009; 60: 270276.

15. Ndisang JF, Jadhav A, Heme oxygenase system enhances insulin sensitivity and glucose metabolism in streptozotocin-induced diabetes. Am J Physiol Endocrinol Metab. 2009; 296: E829-E841.

16. Takada J, Machado MA, Peres SB, Brito LC, BorgesSilva, CN, Costa CE, Fonseca- Alaniz MH, Andreotti S, Lima FB, Neonatal streptozotocin-induced diabetes mellitus: a model of insulin resistance associated with loss of adipose mass. Metabolism 2007; 56: 977-984. 